\title{
Long-term exposure to fine particle matter and all-cause mortality and cause-specific mortality in Japan: the JPHC Study
}

Norie Sawada ${ }^{1 *}$, Tomoki Nakaya ${ }^{2}$, Saori Kashima ${ }^{3}$,Takashi Yorifuji ${ }^{4}$, Tomoya Hanibuchi ${ }^{2}$, Hadrien Charvat $^{1}$, Taiki Yamaji ${ }^{1}$, Motoki Iwasaki ${ }^{1}$, Manami Inoue ${ }^{1}$, Hiroyasu Iso ${ }^{5}$ and Shoichiro Tsugane ${ }^{1}$

\begin{abstract}
Background: Many epidemiological studies have reported the association between exposure to particulate matter and mortality, but long-term prospective studies from Asian populations are sparse. Furthermore, associations at low levels of air pollution are not well clarified. Here, we evaluated associations between long-term exposure to particulate matter $<2.5 \mathrm{\mu g} / \mathrm{m}^{3}\left(\mathrm{PM}_{2.5}\right)$ and mortality in a Japanese cohort with a relatively low exposure level.

Methods: The Japan Public Health Center-based Prospective Study (JPHC Study) is a prospective cohort study of men and women aged 40-69 years in 1990 who were followed up through 2013 for mortality. In this cohort of 87,385

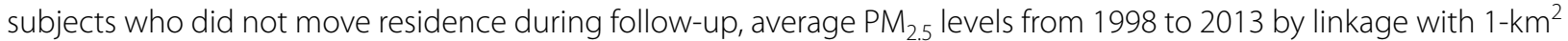
grids of $\mathrm{PM}_{2.5}$ concentration were assigned to the residential addresses of all participants. To avoid exposure misclassification, we additionally evaluated the association between 5-year (1998-2002) cumulative exposure level and mortality during the follow-up period from 2003 to 2013 in 79,078 subjects. Cox proportional hazards models were used to calculate the association of long-term exposure to $\mathrm{PM}_{2.5}$ on mortality, with adjustment for several individual confounding factors.
\end{abstract}

Results: Average $\mathrm{PM}_{2.5}$ was $11.6 \mu \mathrm{g} / \mathrm{m}^{3}$. Average $\mathrm{PM}_{2.5}$ exposure was not associated with all-cause mortality or cancer and respiratory disease mortality. However, average $\mathrm{PM}_{2.5}$ was positively associated with mortality from cardiovascular disease (hazard ratio (HR) of $1.23(95 \% \mathrm{Cl}=1.08-1.40)$ per $1-\mu \mathrm{g} / \mathrm{m}^{3}$ increase; in particular, HR in mortality from cerebrovascular disease was $1.34(95 \% \mathrm{Cl}=1.11-1.61)$ per $1-\mu \mathrm{g} / \mathrm{m}^{3}$ increase. Additionally, these results using cumulative 5-year $\mathrm{PM}_{2.5}$ data were similar to those using average $\mathrm{PM}_{2.5}$ over 15 years.

Conclusions: We found evidence for a positive association between $\mathrm{PM}_{2.5}$ exposure and mortality from cardiovascular disease in a Japanese population, even in an area with relatively low-level air pollution.

Keywords: Particulate matter $<2.5 \mu \mathrm{g} / \mathrm{m}^{3}\left(\mathrm{PM}_{2.5}\right)$, Mortality, Low level exposure, Japan, Prospective study

*Correspondence: nsawada@ncc.go.jp

1 Epidemiology and Prevention Group, Center for Public Health Sciences, National Cancer Center, 5-1-1 Tsukiji, Chuo-ku, 104-0045 Tokyo, Japan Full list of author information is available at the end of the article

\section{Background}

Several prospective cohort studies have reported positive associations between exposure to air pollution, particularly fine particulate matter with a diameter of $2.5 \mu \mathrm{m}$ or less $\left(\mathrm{PM}_{2.5}\right)$, and mortality risk [1-15]. The International Agency for Research on Cancer (IARC) has identified outdoor $\mathrm{PM}_{2.5}$ as a Group I carcinogenic factor for lung cancer $[16,17]$. Furthermore, $\mathrm{PM}_{2.5}$ exposure 
is concluded to be a "modifiable factor contributing to cardiovascular morbidity and mortality" by the American Heart Association writing group [18]. Additionally, a meta-analysis and systematic review recently reported that there is clear evidence that $\mathrm{PM}_{2.5}$ is associated with increased all-cause mortality, and mortality from cardiovascular disease, lung cancer and respiratory disease, based on around 20 cohort studies [3]. However, many of these studies were conducted in Western countries, primarily in North America and Europe. Although the meta-analysis reported a summary risk ratio for all-cause mortality per $10 \mu \mathrm{g} / \mathrm{m}^{3}$ of 1.07 (95\% confidence interval (CI) 1.04-1.11) in the Western Pacific region, this was based on only three studies (Taiwan, China and Hong Kong) [3, 6, 7, 19]. Furthermore, the meta-analysis also suggested that $\mathrm{PM}_{2.5}$ is associated with increased risk for mortality at low exposure levels, even below the current WHO guideline exposure level of $10 \mu \mathrm{g} / \mathrm{m}^{3}$ [3].

Outdoor air pollution levels have decreased over the last few decades in developed countries, including America [20], Europe [21] and Japan [22]. This decline highlights the importance of examining the adverse effects of this pollution at low levels.

Our research group, The Japan Public Health Centerbased Prospective Study (JPHC Study), reported in 2013 that particulate matter did not increase the risk of mortality of cardiovascular disease or lung cancer mortality in the Japanese population [23]. However, exposure level in each area in that study was derived from single area using the nearest monitoring station, meaning that nine exposure levels were assigned to nine areas. Accordingly, the study was unable to determine individual exposure levels.

Here, we have updated this JPHC study analysis by improving the assessment of $\mathrm{PM}_{2.5}$ exposure, from the one-point assessment in each study area to substantially higher resolution (approximately $1-\mathrm{km}^{2}$ grids) and by limiting subjects to those who did not move during follow-up. Additionally, we were able to evaluate never smokers due to the extension of the follow-up period and the increased number of deaths in the cohort.

\section{Methods}

\section{Study population}

The study population was derived from the JPHC Study, a population-based cohort which consists of two separate cohorts (I and II) with a total of 140,420 study participants $(68,722$ men and 71,698 women). Details of the study design have been provided elsewhere [24, 25]. Cohort I was launched in 1990 and consists of 61,595 residents from 5 public health center areas, namely Yokote (Akita Prefecture), Ninohe (Iwate Prefecture), Katsushika (Tokyo), Saku (Nagano Prefecture) and Chubu (Okinawa
Prefecture). Cohort II was started in 1993 and includes 78,825 residents from 6 public health center areas, Nagaoka (Niigata Prefecture), Mito (Ibaraki Prefecture), Suita (Osaka Prefecture), Kamigoto (Nagasaki Prefecture), Chuo-higashi (Kochi Prefecture) and Miyako (Okinawa Prefecture). All subjects were aged 40-59 years in Cohort I and 40-69 years in Cohort II at baseline, except in Tokyo-Katsushika and Osaka-Suita, where are located within major cities: in Tokyo-Katsushika, subjects were selected at the time of their 40- or 50-year health checkup, which were conducted by the Katsushika ward; while in the Osaka-Suita area, one group was drawn from residents aged 40 or 50 years who were invited to participate in a comprehensive health checkup program conducted by the city and a second group was randomly selected from the population registry of the city after stratification by sex and 10-year age group. The baseline survey was conducted from 1990 to 1994 in Cohort I and from 1993 to 1995 in Cohort II.

To minimize misclassification of exposure to air pollution, we limited assignment of $\mathrm{PM}_{2.5}$ levels to the 103,639 subjects (50,686 men, 52,953 women) who did not change residential address from that at baseline during followup. Among these, 87,645 (41,489 men, 46,156 women) responded to a questionnaire (response rate $=84.6 \%$ ) regarding lifestyle, diet, past history of diseases, etc. The study protocol conforms to the ethical guidelines of the Declaration of Helsinki and informed consent was obtained from all participants when completing the survey questionnaire. The study protocol including informed consent was approved by the Institutional Review Board of the National Cancer Center (Number 2001-021, 2015085, 2016-154).

\section{Air pollution measurements}

Ambient $\mathrm{PM}_{2.5}$ at the residential address of study participants was assigned through application of a global land use regression (LUR) model. Model construction is described in detail elsewhere [26]; briefly, annual satellite-derived measurements of $\mathrm{PM}_{2.5}$ were converted to near-ground concentrations via the GEOS-Chem transport model and a ground-based sun photometer. Estimates of $\mathrm{PM}_{2.5}$ were generated at a spatial scale of $1 \mathrm{~km}$ $\mathrm{x} 1 \mathrm{~km}\left(0.01^{\circ} \times 0.01^{\circ}\right.$ longitude-latitude $)$ and found to correspond well with ground-based measurements $\left(R^{2}\right.$ : 0.81) [26]. Exposure to $\mathrm{PM}_{2.5}$ was assigned as the average $\mathrm{PM}_{2.5}$ from 1998 to 2013 at the geocoded location of individual residences at baseline, among subjects who were confirmed not to have moved. We excluded 260 participants who had missing $\mathrm{PM}_{2.5}$ concentrations for any year during follow-up. After these exclusions, 87,385 subjects (41,362 males and 46,023 females) remained for final analysis. 
We evaluated two types of $\mathrm{PM}_{2.5}$ concentration. The primary exposure variable used the average $\mathrm{PM}_{2.5}$ level over the period. We evaluated the association between average exposure level (from 1998 to 2013) and mortality in the 87,385 subjects during the follow-up period (1990-2013). This exposure may not have been appropriate due to a lack of data from 1990 to 1997, and this may have caused misclassification. To avoid this misclassification, we additionally created a second exposure variable - the cumulative $\mathrm{PM}_{2.5}$ level for 5 years (1998-2002) with which we evaluated the association between 5 -year cumulative exposure level and mortality during followup period from 2003 to 2013 in 79,078 subjects, after excluding subjects who were lost to follow-up or died before 2003 .

\section{Follow-up and mortality}

We followed all registered subjects from questionnaire response date to 31 December 2013. Changes in residence status were identified in each study area through the residential registry. After we identified the survival status of subjects, we linked records with vital statistics data from the Ministry of Health, Labor, and Welfare, with permission. Registration of deaths is mandatory under the Family Registration Law, and the registry is nearly $100 \%$ complete in Japan. Causes of death were coded according to the 10th International Classification of Diseases (ICD-10). For cause-specific mortality analyses, deaths from cancer (C00-C99), cardiovascular disease (I01-199) and respiratory disease (J00-J99) were identified. Further, we also evaluated cause of death in more detail for lung cancer (C34), ischemic heart disease (IHD) (I20-I25), cerebrovascular disease (I60-I69), pneumonia and influenza (J10-J22) and chronic obstructive pulmonary disease (COPD) and associated conditions (J40-J47).

\section{Statistical analysis}

Cox proportional hazards models were used to quantify the association between $\mathrm{PM}_{2.5}$ level and mortality. Hazard ratios (HRs) and 95\% confidence intervals (CIs) were calculated for every $1-\mu \mathrm{g} / \mathrm{m}^{3}$ increase in $\mathrm{PM}_{2.5}$ exposure levels.

As primary analysis, we first analyzed the dataset $(\mathrm{N}=87,385,41,362$ men and 46,023 women) for the follow-up period (days) 1990-2013 by using average annual $\mathrm{PM}_{2.5}$ levels from 1998 to 2013. Person-years of followup were calculated from the date of response to the baseline questionnaire to the end of follow-up (December 31st 2013), loss to follow-up or date of death, whichever occurred first. We first adjusted for sex, age (continuous) and public health center (PHC) (11 areas by strata) using the baseline questionnaire. We then further adjusted for confounding factors smoking status (never, past, current smokers $(<20$ cigarettes/day, $\geqq 20$ cigarettes /day), missing), alcohol drinking (never, occasional, $<150 \mathrm{~g}$ ethanol/week, 150-300 g ethanol/week, $\geqq 300 \mathrm{~g}$ ethanol/ week, missing), body mass index $(<18.5,18.5-23,23-25$, $\geqq 25$, missing), occupation (primary, secondary, tertiary, housewife or unemployed, missing), coffee drinking (1 cup/day, 1-2 cups/day, 3-4 cups/day, $\geqq 5$ cups/day, missing), passive smoking at home/workplace (yes, no, missing), and a past history of cardiovascular disease (yes, no), cancer (yes, no) or diabetes mellitus (yes, no). Furthermore, we adjusted for birth year to control betweencohort effects.

Next, for sensitivity analysis, we analyzed a dataset $(\mathrm{N}=79,078,36,665$ men and 42,413 women) for the follow-up period (days) from 2003 to 2013 by using 5 -year cumulative $\mathrm{PM}_{2.5}$ levels (1998-2002). Person-years of follow-up were calculated from January 1st 2003 to the end of follow-up (December 31st 2013), loss to follow-up or date of death, whichever occurred first. We adjusted for the same kind of variables as in the primary analysis, data for which were collected in the 10-yr follow-up survey (in 2000 for Cohort I and in 2003 for Cohort II).

We also calculated the association between average $\mathrm{PM}_{2.5}$ (1998-2003) and cumulative $\mathrm{PM}_{2.5}$ (5-year) levels and mortality in never smokers. Whenever a significant association was found between $\mathrm{PM}_{2.5}$ (1998-2003) or cumulative $\mathrm{PM}_{2.5}$ (5-year) levels and the mortality outcomes under study, we assessed the potential nonlinearity of this relationship through a likelihood ratio test comparing the current model (i.e., including a linear effect of the $\mathrm{PM}_{2.5}$ variable) and a model in which the effect of the variable was modelled by a restricted cubic spline with a knot placed at the median of its distribution. All $\mathrm{p}$ values were two-sided. Analyses were conducted using the PHREG command of the SAS software (version 9.3; SAS Institute Inc., Cary, NC, USA), as well as the 'survival' and 'spline' $\mathrm{R}$ packages ( $\mathrm{R}$ statistical software version 4.1.0; $R$ Development Core Team, 2021).

\section{Results}

The baseline characteristics of total subjects and never smokers are listed in Table 1. Annual average $\mathrm{PM}_{2.5}$ exposure ( \pm Standard Deviation) was $11.6( \pm 2.9) \mu \mathrm{g} /$ $\mathrm{m}^{3}$. The interquartile range was from 9.24 to 12.98 and the minimum and maximum were 7.18 and $17.89 \mu \mathrm{g} / \mathrm{m}^{3}$, respectively. Among total subjects, mean age ( \pm standard deviation) was $51.9( \pm 7.9)$ and ever smokers accounted for $40.3 \%$. For never smokers, the proportion of women was $81.3 \%$, while that of regular drinkers, coffee drinkers, past history of diabetes mellitus, cardiovascular diseases and cancer were less compared with total subjects. 
Table 1 Demogphaphic characteristics of study participants at baseline

\begin{tabular}{|c|c|c|}
\hline & Subjects at baseline & Never smokers at baseline \\
\hline Number of subjects & 87,385 & 51,820 \\
\hline Age, mean \pm SD & $51.9 \pm 7.9$ & $52.0 \pm 7.8$ \\
\hline Sex, women, \% & 52.7 & 81.3 \\
\hline Ever smokers, \% & 40.3 & - \\
\hline Current smokers, $\%$ & 28.0 & - \\
\hline Regular drinker, \% & 37.3 & 19.2 \\
\hline Coffee drinker ( $\geqq 3$ cups/day), $\%$ & 10.8 & 7.6 \\
\hline Leisure exercise ( $\geqq 1$ time/week), \% & 18.2 & 18.3 \\
\hline Passive smoking at home/workplace (almost none), \% & 25.6 & 30.5 \\
\hline Past history of diabetes mellitus, $\%$ & 4.6 & 3.3 \\
\hline Past history of cardiovasular disease, $\%$ & 0.6 & 0.4 \\
\hline Past history of cancer, $\%$ & 2.2 & 2.5 \\
\hline Primary industry, $\%$ & 21.1 & 20.6 \\
\hline Body mass index, mean $\pm \mathrm{SD}$ & $23.4 \pm 3.0$ & $23.5 \pm 3.2$ \\
\hline Mean PM2.5 from 1998 to 2013, mean \pm SD & $11.6 \pm 2.9$ & $11.5 \pm 3.0$ \\
\hline Mean PM2.5 from 1998 to 2013, interquartile range & $9.24-12.98$ & $9.19-12.94$ \\
\hline
\end{tabular}

The HRs for all cause and cause-specific mortality are shown in Table $2 . \mathrm{PM}_{2.5}$ was not statistically significantly associated with increased risk of all cause mortality; HR for all cause mortality was 1.02 (0.95-1.10). For specific cause mortality, however, $\mathrm{PM}_{2.5}$ was positively associated with cardiovascular disease: the multivariate $\mathrm{HR}$ of a $1-\mu \mathrm{g} / \mathrm{m}^{3}$ increase in $\mathrm{PM}_{2.5}$ for cardiovascular disease mortality was 1.23 (95\%CI:1.08-1.40), respectively. In particular, $\mathrm{PM}_{2.5}$ exposure was strongly associated with cerebrovascular disease mortality; HRs $(95 \% \mathrm{CI})$ of a $1 \mu \mathrm{g} / \mathrm{m}^{3}$ increase in $\mathrm{PM}_{2.5}$ for cerebrovascular disease mortality was 1.34 (1.11-1.61). Figures 1 and 2 shows the spline-based modelling of the effect of average $\mathrm{PM}_{2.5}$ (Fig. 1) and cumulative $\mathrm{PM}_{2.5}$ from 1998 to 2002 (Fig. 2) and cardiovascular disease mortality or cerebrovascular disease mortality in the whole study population. In all cases, the relationships monotonously increased with $\mathrm{PM}_{2.5}$ exposure level and did not differ significantly from the linear relationships shown in Tables 2 and 3. We did not find associations between $\mathrm{PM}_{2.5}$ and other mortality, namely that due to cancer, lung cancer, ischemic diseases, respiratory disease including pneumonia and influenza, or COPD and allied conditions. We also found similar results in never smokers.

In the sensitivity analysis, to minimize the effects of misclassification due to subjects who censored during follow-up, we used cumulative exposure level before follow-up from 2003 (Table 3). Cumulative average $\mathrm{PM}_{2.5}$ exposure ( \pm Standard Deviation) was $10.5( \pm 3.1) \mu \mathrm{g} /$ $\mathrm{m}^{3}$ and the interquartile range was from 8.28 to 12.68
(Supplemental Table). These results using cumulative 5-year $\mathrm{PM}_{2.5}$ data are similar to those using average $\mathrm{PM}_{2.5}$ over 15 years.

The results did not change when we adjusted for birth year to control for between-cohort effects.

\section{Discussion}

Overall, the results of this study suggest that $\mathrm{PM}_{2.5}$ is not associated with all cause mortality, but that $\mathrm{PM}_{2.5}$ is positively associated with cardiovascular disease mortality, especially cerebrovascular disease mortality, even in an area with relatively low exposure.

The positive association between $\mathrm{PM}_{2.5}$ and cardiovascular disease mortality is consistent with the results of recent meta-analysis in 2020, which showed the combined effect estimate per $10 \mu \mathrm{g} / \mathrm{m}^{3}$ increase in $\mathrm{PM}_{2.5}$ was 1.11 (1.09-1.14) from 21 studies [3]. Possible mechanisms of this increasing risk of cardiovascular disease with $\mathrm{PM}_{2.5}$ are considered to involve increasing systemic oxidative stress, endothelial dysfunction and progression of atherosclerosis $[18,27]$. Given the results from metaanalysis and mechanisms, these are plausible explanation for our positive association between $\mathrm{PM}_{2.5}$ and cerebrovascular diseases, although a recent prospective Japanese cohort reported that $\mathrm{PM}_{2.5}$ was not statistically significantly associated with an increase in the risk of mortality due to circulatory disease (I10-I69) nor cerebrovascular disease [15].

Our study showed a larger HR per $1-\mu \mathrm{g} / \mathrm{m}^{3}$ increase in $\mathrm{PM}_{2.5}$ for cardiovascular disease $(\mathrm{HR}=1.23$ 


\section{Cardiovascular diseases (101-199)}

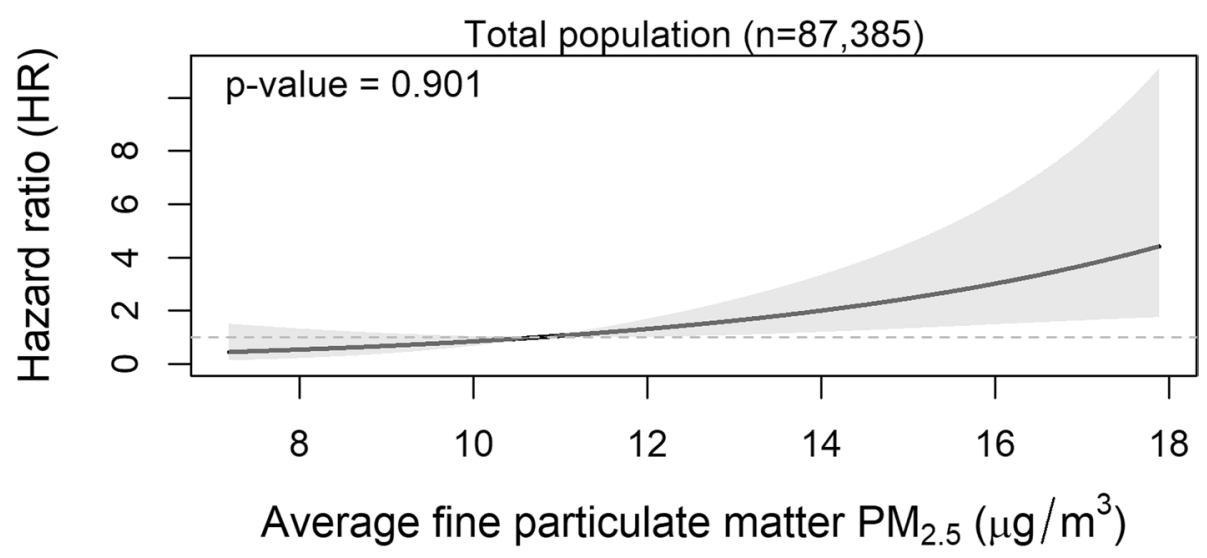

Cerebrovascular diseases (160-169)

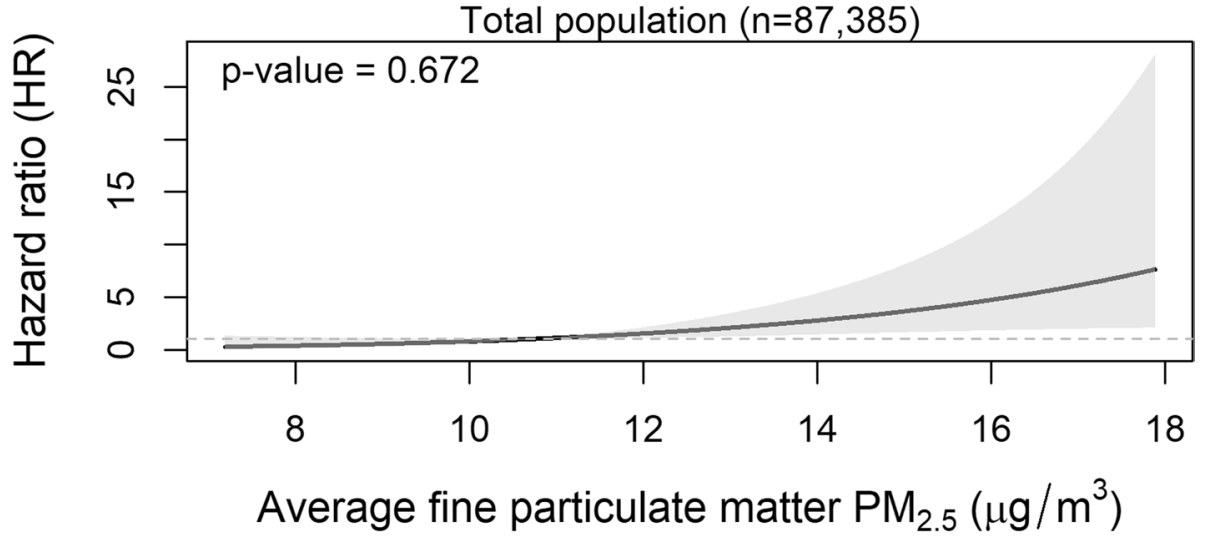

Fig. 1 Exposure-response effect of average fine particulate matter $\mathrm{PM}_{2.5}$ exposure from 1998 to 2013 on cardiovascular disease mortality (upper panel) and cerebrovascular disease mortality (lower panel) in the whole study population. The curves are based on a restricted cubic spline with a knot placed at the median of the distribution of average $\mathrm{PM}_{2.5}$ exposure and the $\mathrm{p}$-values refer to the test of non-linearity of the exposure-response relationship obtained through a likelihood ratio test comparing the depicted spline-based model with a model including only a linear effect of the variable

$(95 \% \mathrm{CI}=1.08-1.40))$ than a meta-analysis $(\mathrm{HR}=1.011$ $(95 \% \mathrm{CI}=1.009-1.014)$ per $1-\mu \mathrm{g} / \mathrm{m}^{3}$ increase). However, the meta-analysis also showed that summary relative risks (RRs) tended to be larger in studies with mean $\mathrm{PM}_{2.5}$ concentrations below 12 or $10 \mu \mathrm{g} / \mathrm{m}^{3}$, for which the corresponding $R R$ per $10-\mu \mathrm{g} / \mathrm{m}^{3}$ increase was 1.12 (1.08-1.17) or 1.17 (1.12-1.23), respectively [3]. Additionally, the "45 and Up Study" of low-level air pollution in Australia showed similar mortality results to ours, with an HR of $1.05(95 \% \mathrm{CI}=0.98-1.12)$ per $1-\mu \mathrm{g} / \mathrm{m}^{3}$ increase in $\mathrm{PM}_{2.5}$ versus our present $\mathrm{HR}$ of $1.02(95 \% \mathrm{CI}=0.95-1.10)$, albeit that these researchers did not analyze the risk of cardiovascular disease [28]. Although it is not clear why risk was larger with a lower exposure level than with a high level, our results are nevertheless supported by these previous studies [3, 28].

In our study, the HR of cerebrovascular disease was higher than that of ischemic heart disease. In contrast, a recent meta-analysis reported that the combined effect estimate of ischemic heart disease was slightly greater than that of cerebrovascular disease [3]. This difference in results might be partly explained by the difference in the subtype of cardiovascular disease mortality between Japan and Western countries, wherein mortality of coronary heart disease is lower in East Asian than Western countries and stroke is higher [29].

Outdoor air pollution contains a number of carcinogens, and the International Agency for Research on Cancer (IARC) has concluded that exposure to outdoor air 


\section{Cardiovascular diseases (101-199)}

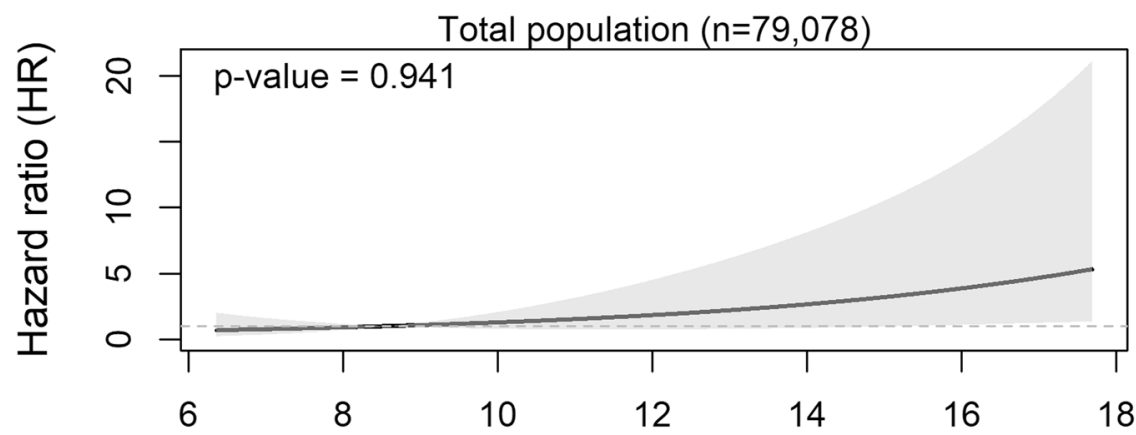

\section{Cumulative exposure to fine particulate matter $\mathrm{PM}_{2.5}\left(\mu \mathrm{g} / \mathrm{m}^{3}\right)$}

\section{Cerebrovascular diseases (160-169)}

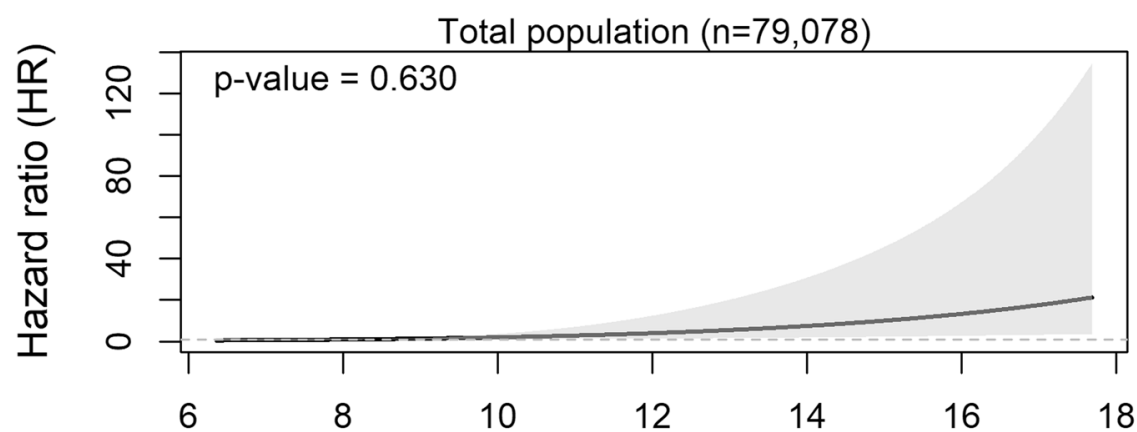

\section{Cumulative exposure to fine particulate matter $\mathrm{PM}_{2.5}\left(\mu \mathrm{g} / \mathrm{m}^{3}\right)$}

Fig. 2 Exposure-response effect of cumulative fine particulate matter $\mathrm{PM}_{2.5}$ exposure from 1998 to 2002 on cardiovascular disease mortality (upper panel) and cerebrovascular disease mortality (lower panel) from 2003 onwards in the whole study population. The curves are based on a restricted cubic spline with a knot placed at the median of the distribution of cumulative $\mathrm{PM}_{2.5}$ exposure and the $\mathrm{p}$-values refer to the test of non-linearity of the exposure-response relationship obtained through a likelihood ratio test comparing the depicted spline-based model with a model including only a linear effect of the variable

Table 2 Adjusted HRs for a 1- $\mu \mathrm{g} / \mathrm{m} 3$ increase in fine particulate matter PM2.5 (Average from 1998-2013) and 95\% Cls for all cause and cause-specific mortality

\begin{tabular}{|c|c|c|c|c|c|c|}
\hline & & \multicolumn{2}{|c|}{ Total subjects $(\mathrm{N}=87,385)$} & \multirow[b]{2}{*}{ Death $(\mathrm{N})$} & \multicolumn{2}{|c|}{ Never smokers $(N=51,820)$} \\
\hline & Death $(\mathrm{N})$ & $\begin{array}{c}\text { Age and sex adjusted } \\
\text { HR }(95 \% \mathrm{Cl})\end{array}$ & $\begin{array}{c}\text { Multivariables adjusted } \\
\text { HR }(95 \% \mathrm{Cl})^{*}\end{array}$ & & $\begin{array}{c}\text { Age and sex adjusted HR } \\
(95 \% \mathrm{Cl})\end{array}$ & $\begin{array}{c}\text { Multivariables adjusted } \\
\qquad \mathrm{HR}(95 \% \mathrm{Cl})^{*}\end{array}$ \\
\hline All cause & 17,838 & $1.01(0.94-1.08)$ & $1.02(0.95-1.10)$ & 7,606 & $1.03(0.92-1.14)$ & $1.04(0.94-1.16)$ \\
\hline \multicolumn{7}{|l|}{ Cause-specific mortality } \\
\hline Cancer (C00-C97) & 7,285 & $0.93(0.83-1.04)$ & $0.95(0.85-1.06)$ & 2,988 & $0.92(0.77-1.10)$ & $0.95(0.80-1.13)$ \\
\hline Lung cancer (C34) & 1449 & $0.98(0.77-1.24)$ & $1.02(0.80-1.29)$ & 319 & $0.97(0.61-1.54)$ & $1.03(0.65-1.65)$ \\
\hline Cardiovascular disease (101-199) & 4,537 & $1.22(1.07-1.39)$ & $1.23(1.08-1.40)$ & 2,031 & $1.31(1.09-1.58)$ & $1.32(1.09-1.60)$ \\
\hline Ischemic heart disease (120-125) & 1,106 & $1.19(0.91-1.55)$ & $1.18(0.90-1.56)$ & 433 & $1.27(0.85-1.90)$ & $1.25(0.82-1.89)$ \\
\hline Cerebrovascular disease $(160-169)$ & 1,817 & $1.33(1.10-1.61)$ & $1.34(1.11-1.61)$ & 848 & $1.53(1.16-2.01)$ & $1.56(1.18-2.06)$ \\
\hline Respiratory disease (J00- J99) & 1,743 & $0.82(0.65-1.04)$ & $0.82(0.65-1.05)$ & 645 & $0.80(0.55-1.15)$ & $0.81(0.56-1.17)$ \\
\hline Pnuemonia and influenza (J10-J22) & 916 & $0.85(0.61-1.20)$ & $0.85(0.60-1.20)$ & 362 & $0.91(0.55-1.50)$ & $0.92(0.56-1.52)$ \\
\hline COPD and allied conditions (J40-J47) & 284 & $0.85(0.48-1.49)$ & $0.93(0.52-1.65)$ & 72 & $1.10(0.41-2.90)$ & $1.17(0.43-3.18)$ \\
\hline
\end{tabular}

*Adjusted for age, sex, area (11 area by strata), smoking status (never, past, $<20$ cigarettes/day, $\geqq 20$ cigarettes/day), alcohol drinking (never, occasional, $<150 \mathrm{~g} /$ week, $150-300 \mathrm{~g} /$ week, $\geqq 300 \mathrm{~g} /$ week) , body mass index $(<18.5,18.5-23,23-25, \geq 25)$, occcupation (primary, secondary, tertiary, housewife or unemployed ), coffee intake $(<1$ cup/day, 1-2 cups/day, 3-4 cups/day, $\geqq 5$ cups/day), sports ( $\leqq 3$ days/month, 1-4 days/week, almost everyday), passive smoking at home/workplace, and past history of cardiovascular disease, cancer, or diabetes mellitus 
Table 3 Adjusted HRs for a 1- $\mu \mathrm{g} / \mathrm{m} 3$ increase in fine particulate matter PM2.5 (Cumulative average from 1998-2002) and 95\% Cls for all cause and cause-specific mortality

\begin{tabular}{|c|c|c|c|c|c|c|}
\hline & & \multicolumn{2}{|c|}{ Total subjects $(\mathrm{N}=79,078)$} & \multirow[b]{2}{*}{ Death $(\mathrm{N})$} & \multicolumn{2}{|c|}{ Never smokers $(\mathrm{N}=49,352)$} \\
\hline & Death $(N)$ & $\begin{array}{c}\text { Age and sex adjusted } \\
\text { HR }(95 \% \mathrm{Cl})\end{array}$ & $\begin{array}{c}\text { Multivariables adjusted } \\
\text { HR }(95 \% \mathrm{Cl}) *\end{array}$ & & $\begin{array}{c}\text { Age and sex adjusted HR } \\
(95 \% \mathrm{Cl})\end{array}$ & $\begin{array}{c}\text { Multivariables adjusted } \\
\text { HR }(95 \% \mathrm{Cl}) *\end{array}$ \\
\hline All cause & 11,325 & $1.03(0.96-1.11)$ & $1.03(0.96-1.11)$ & 5,096 & $1.07(0.95-1.19)$ & $1.08(0.97-1.21)$ \\
\hline \multicolumn{7}{|l|}{ Cause-specific mortality } \\
\hline Cancer (C00-C97) & 4,420 & $0.92(0.81-1.04)$ & $0.92(0.81-1.04)$ & 1,872 & $0.89(0.73-1.08)$ & $0.89(0.73-1.09)$ \\
\hline Lung cancer (C34) & 922 & $1.09(0.86-1.38)$ & $1.09(0.86-1.38)$ & 199 & $0.90(0.55-1.49)$ & $0.89(0.53-1.49)$ \\
\hline Cardiovascular disease (101-199) & 2,973 & $1.21(1.06-1.39)$ & $1.20(1.05-1.37)$ & 1,493 & $1.26(1.04-1.52)$ & $1.25(1.04-1.51)$ \\
\hline Ischemic heart disease (120-125) & 727 & $1.16(0.87-1.53)$ & $1.14(0.86-1.51)$ & 324 & $1.26(0.87-1.85)$ & $1.30(0.90-1.89)$ \\
\hline Cerebrovascular disease (160-169) & 1,129 & $1.39(1.13-1.69)$ & $1.37(1.12-1.68)$ & 548 & $1.53(1.20-1.96)$ & $1.56(1.21-2.01)$ \\
\hline Respiratory disease (J00-J99) & 1,296 & $0.85(0.67-1.06)$ & $0.84(0.66-1.05)$ & 504 & $0.98(0.68-1.41)$ & $1.00(0.69-1.44)$ \\
\hline Pnuemonia and influenza (J10-J22) & 689 & $1.01(0.73-1.39)$ & $0.98(0.71-1.36)$ & 289 & $1.24(0.80-1.92)$ & $1.23(0.79-1.91)$ \\
\hline COPD and allied conditions (J40-J47) & 191 & $0.86(0.49-1.53)$ & $0.82(0.46-1.48)$ & 52 & $0.87(0.27-2.83)$ & $0.90(0.27-3.05)$ \\
\hline
\end{tabular}

*Adjusted for age, sex, area, smoking status (never, past, $<20$ cigarettes/day, $\geqq 20$ cigarettes/day), alcohol drinking (never, occasional, $<150 \mathrm{~g} /$ week, $150-300 \mathrm{~g} /$ week, $\geqq 300 \mathrm{~g} /$ week) , body massindex (<18.5, 18.5-23, 23-25, $\geqq 25)$, occcupation (primary, secondary, tertiary, housewife or unemployed ), coffee intake (<1 cup/day, $1-2$ cups/day, 3-4 cups/day, $\geqq 5$ cups/day), sports ( $\leqq 3$ days/month, 1-4days/week, almost everyday), passive smoking (any), and past history of cardiovascular disease, cancer, or diabetes mellitus.

pollution and to particulate matter in outdoor air is carcinogenic to humans (Group 1) and is carcinogenic for lung cancer $[16,17]$. A recent meta-analysis of 15 studies also reported a combined effect estimate per 10- $\mathrm{g}$ / $\mathrm{m}^{3}$ increase in $\mathrm{PM}_{2.5}$ of 1.12 (1.07-1.16) [3]. In contrast, our present study did not show that $\mathrm{PM}_{2.5}$ increased risk of lung cancer mortality. We also found that HR was not changed when we limited analysis to never smokers. This finding is not accordant with other Japanese cohorts conducted in one prefecture [15] and three prefectures [30], which reported elevated HRs for lung cancer mortality in association with $\mathrm{PM}_{2.5}$. The possibility of a discrepancy might be explained by differences in exposure level. The $\mathrm{PM}_{2.5}$ levels in these studies were higher than ours: average exposure level (inter-area range) from Katanoda et al. was 16.8 to $41.9 \mu \mathrm{g} / \mathrm{m}^{3}$ [30] while Yorifuji et al. reported an average $\mathrm{PM}_{2.5}$ level of $14.0 \mu \mathrm{g} / \mathrm{m}^{3}$ [15], which is slightly higher than our average level. It might be difficult to evaluate the adverse effects of air pollution on lung cancer and respiratory disease in areas with a low exposure level. We should also caution about the difference in the number of deaths between cerebrovascular disease and lung cancer: the positive association with cardiovascular disease mortality might have been revealed by the larger number of deaths from cardiovascular disease.

Our JPHC group previously reported that $\mathrm{PM}_{2.5}$ was not associated with cardiovascular disease mortality [23], the exposure level for which was assigned using the level at the nearest monitoring station in each public health center area. Rather, our study showed a stronger association between air pollution and cardiovascular disease by using a more accurate method and larger number of cases over longer follow-up, and by excluding subjects who moved residence after baseline. Moreover, our results using cumulative average are similar. According to the European Study of Cohorts for Air Pollution Effects (ESCAPE), which reported a positive association between $\mathrm{PM}_{2.5}$ and lung cancer incidence, the ESCAPE study showed a stronger association when restricted to subjects who had lived at the same residence throughout follow-up [31] due to the minimization of misclassification. Our improved evaluation might have identified a clearer association.

The major strengths of this study are its use of a general population with a high response rate $(85 \%)$ and its prospective design. Additionally, we were able to adjust for possible confounding factors at the individual level. In contrast, several limitations are also present. First, we did not consider exposure level at other places or workplaces due to a lack of information. this raises the possibility of exposure misclassification, because almost no people stay home all day and some are exposed at the workplace, although it is one of best ways identified to date to evaluate individual air pollution exposure level based on their individuals residency. Second, we could not include participants who moved out, because we have not yet applied the geocode to the addresses to which they moved. If a change in residential address is associated with exposure level, this might introduce a bias in the study. Further study using time-varying analysis which combines $\mathrm{PM}_{2.5}$ levels at both the original residence and that after moving out among all participants is needed. Third, we did not have information on early exposure, which might have lead to a degree of misclassification. However, we assumed that the spatial $\mathrm{PM}_{2.5}$ was preserved in the study area, because average $\mathrm{PM}_{2.5}(1998-2013)$ was highly correlated with single year data (0.88-0.99), and because the observed correlation coefficients between concentrations in different years were also high (0.90-0.97). Moreover, the 
sensitivity analyses which used the cumulative $5 \mathrm{yr}$ exposure were robust. We therefore consider that this assumption is reasonable. Fourth, we did not take full account of socioeconomic status, although we adjusted individual job status. Additionally, we adjusted by individual educational level in some subjects whose data were collected by questionnaire, but results were not substantially changed. Fifth, we did not consider change in lifestyle over time, albeit that we did adjust for possible confounding factors at the individual level. Finally, the possibility of residual confounding cannot be ruled out, because confounding factors we adjusted were collected as self-reported.

In conclusion, the present study found evidence that for a positive association between $\mathrm{PM}_{2.5}$ exposure and cardiovascular disease mortality in Japanese population, even in a relatively low-level air pollution area.

\section{Supplementary Information}

The online version contains supplementary material available at https://doi. org/10.1186/s12889-022-12829-2.

\section{Additional file 1.}

\section{Acknowledgements}

We thank Drs George S Downward, Roel Vermeulen at Utrecht University for their help in applying air pollution data. JPHC members are listed at the following site (as of April 2020); https://epi.ncc.go.jp/en/jphc/781/8510.html.

\section{Authors' contributions \\ NS contributed to the conception of the study; the design, acquisition, analysis, and interpretation of data; and was a major contributor to writing the manuscript. TN, SK, TY and TH interpreted the data and substantively critically reviewed them. $\mathrm{HC}$ contributed to analysis of the data and interpretation of the results. TY, Mol, Mal, $\mathrm{HI}$ and ST contributed to the acquisition of data and ST supervised and acquired funding. All authors read and approved the final manuscript.}

\section{Funding}

This study was supported by JSPS KAKENHI Grant Numbers JP15K08721 and JP18K10116, National Cancer Center Research and Development Fund (since 2011) and a Grant-in-Aid for Cancer Research from the Ministry of Health, Labour and Welfare of Japan (from 1989 to 2010).

\section{Availability of data and materials}

We cannot publicly provide individual data due to participant privacy, according to ethical guidelines in Japan. Additionally, the informed consent we obtained does not include a provision for publicly sharing data. Instructions on how to submit an application to gain access to JPHC data and/or biospecimens are available at https://epi.ncc.go.jp/en/jphc/805/8155.html.

\section{Declarations}

Ethics approval and consent to participate

The study protocol conforms to the ethical guidelines of the Declaration of Helsinki and informed consent was obtained from all participants when completing the survey questionnaire. The study protocol including informed consent was approved by the Institutional Review Board of the National Cancer Center (Number 2001-021, 2015-085, 2016-154).

\section{Consent for publication}

Not applicable.

\section{Competing interests}

The authors declare that they have no competing interests.

\section{Author details}

${ }^{1}$ Epidemiology and Prevention Group, Center for Public Health Sciences, National Cancer Center, 5-1-1 Tsukiji, Chuo-ku, 104-0045 Tokyo, Japan. ${ }^{2}$ Graduate School of Environmental Studies, Tohoku University, Sendai, Japan. ${ }^{3}$ Environmental Health Sciences Laboratory, Graduate School of Advanced Science and Engineering, Hiroshima University, Hiroshima, Japan. ${ }^{4}$ Department of Epidemiology, Dentistry and Pharmaceutical Sciences, Okayama University Graduate School of Medicine, Okayama, Japan. ${ }^{5}$ Public Health Graduate School of Medicine, Osaka University, Suita, Japan.

Received: 26 May 2021 Accepted: 18 February 2022

Published online: 08 March 2022

\section{References}

1. Hoek G, Krishnan RM, Beelen R, Peters A, Ostro B, Brunekreef B, Kaufman JD. Long-term air pollution exposure and cardio- respiratory mortality: a review. Environ Health. 2013;12(1):43.

2. Beelen R, Raaschou-Nielsen O, Stafoggia M, Andersen ZJ, Weinmayr G, Hoffmann B, Wolf K, Samoli E, Fischer P, Nieuwenhuiisen M, et al. Effects of long-term exposure to air pollution on natural-cause mortality: an analysis of 22 European cohorts within the multicentre ESCAPE project. Lancet. 2014;383(9919):785-95.

3. Chen J, Hoek G. Long-term exposure to PM and all-cause and causespecific mortality: A systematic review and meta-analysis. Environ Int. 2020;143:105974.

4. Li T, Zhang Y, Wang J, Xu D, Yin Z, Chen H, Lv Y, Luo J, Zeng Y, Liu Y, et al. All-cause mortality risk associated with long-term exposure to ambient PM2.5 in China: a cohort study. Lancet Public Health. 2018;3(10):e470-7.

5. Christidis T, Erickson AC, Pappin AJ, Crouse DL, Pinault LL, Weichenthal SA, Brook JR, van Donkelaar A, Hystad P, Martin RV, et al. Low concentrations of fine particle air pollution and mortality in the Canadian Community Health Survey cohort. Environ Health. 2019;18(1):84.

6. Yang Y, Tang R, Qiu H, Lai PC, Wong P, Thach TQ, Allen R, Brauer M, Tian L, Barratt B. Long term exposure to air pollution and mortality in an elderly cohort in Hong Kong. Environ Int. 2018;117:99-106.

7. Yin P, Brauer M, Cohen A, Burnett RT, Liu J, Liu Y, Liang R, Wang W, Qi J, Wang $\mathrm{L}$, et al. Long-term Fine Particulate Matter Exposure and Nonaccidental and Cause-specific Mortality in a Large National Cohort of Chinese Men. Environ Health Perspect. 2017;125(11):117002.

8. Thurston GD, Ahn J, Cromar KR, Shao Y, Reynolds HR, Jerrett M, Lim CC, Shanley R, Park Y, Hayes RB. Ambient Particulate Matter Air Pollution Exposure and Mortality in the NIH-AARP Diet and Health Cohort. Environ Health Perspect. 2016;124(4):484-90.

9. Di Q, Wang Y, Zanobetti A, Wang Y, Koutrakis P, Choirat C, Dominici F, Schwartz JD. Air Pollution and Mortality in the Medicare Population. N Engl J Med. 2017;376(26):2513-22.

10. Cesaroni G, Badaloni C, Gariazzo C, Stafoggia M, Sozzi R, Davoli M, Forastiere F. Long-term exposure to urban air pollution and mortality in a cohort of more than a million adults in Rome. Environ Health Perspect. 2013;121(3):324-31.

11. Turner MC, Jerrett M, Pope CA, Krewski D, Gapstur SM, Diver WR, Beckerman BS, Marshall JD, Su J, Crouse DL, et al. Long-Term Ozone Exposure and Mortality in a Large Prospective Study. Am J Respir Crit Care Med. 2016;193(10):1134-42.

12. Villeneuve PJ, Weichenthal $S A$, Crouse $D$, Miller $A B$, To T, Martin RV, van Donkelaar A, Wall C, Burnett RT. Long-term Exposure to Fine Particulate Matter Air Pollution and Mortality Among Canadian Women. Epidemiology. 2015;26(4):536-45.

13. Lepeule J, Laden F, Dockery D, Schwartz J. Chronic exposure to fine particles and mortality: an extended follow-up of the Harvard Six Cities study from 1974 to 2009. Environ Health Perspect. 2012;120(7):965-70.

14. Pinault LL, Weichenthal S, Crouse DL, Brauer M, Erickson A, Donkelaar AV, Martin RV, Hystad P, Chen $\mathrm{H}$, Fines $\mathrm{P}$, et al. Associations between fine particulate matter and mortality in the 2001 Canadian Census Health and Environment Cohort. Environ Res. 2017;159:406-15. 
15. Yorifuji T, Kashima S, Tani Y, Yamakawa J, Doi H. Long-term exposure to fine particulate matter and natural-cause and cause-specific mortality in Japan. Environ Epidemiol. 2019;3:e051.

16. IARC working group on the evaluation of carcinogenic risks to humans, IARC Monographs: Outdoor Air Pollution, vol. 109: International Agency for Research on Cancer; 2016.

17. Hamra GB, Guha N, Cohen A, Laden F, Raaschou-Nielsen O, Samet JM, Vineis P, Forastiere F, Saldiva P, Yorifuji T, et al. Outdoor particulate matter exposure and lung cancer: a systematic review and meta-analysis. Environ Health Perspect. 2014;122(9):906-11.

18. Brook RD, Rajagopalan S, Pope CA 3, Brook JR, Bhatnagar A, Diez-Roux AV, Holguin F, Hong Y, Luepker RV, Mittleman MA, et al. Particulate matter air pollution and cardiovascular disease: An update to the scientific statement from the American Heart Association. Circulation. 2010;121(21):2331-78.

19. Tseng E, Ho WC, Lin MH, Cheng TJ, Chen PC, Lin HH. Chronic exposure to particulate matter and risk of cardiovascular mortality: cohort study from Taiwan. BMC Public Health. 2015;15:936.

20. Air Pollutant Emissions Trends Data [https://www.epa.gov/air-emissionsinventories/air-pollutant-emissions-trends-data]

21. Trends in concentrations of PM2.5 in the UK, 2009 to 2019 [https:// www.gov.uk/government/statistics/air-quality-statistics/concentrat ions-of-particulate-matter-pm10-and-pm25]

22. Wakamatsu SM, Ito T. Air Pollution Trends in Japan between 1970 and 2012 and Impact of Urban Air Pollution Countermeasures. Asian J Atmospheric Environ. 2013;7-4:177-90.

23. Nishiwaki Y, Michikawa T, Takebayashi T, Nitta H, Iso H, Inoue M, Tsugane S, Japan Public Health Center-based Prospective Study G. Long-term exposure to particulate matter in relation to mortality and incidence of cardiovascular disease: the JPHC Study. J Atheroscler Thromb. 2013;20(3):296-309.

24. Watanabe S, Tsugane S, Sobue T, Konishi M, Baba S. Study design and organization of the JPHC study. Japan Public Health Center-based Prospective Study on Cancer and Cardiovascular Diseases. J Epidemiol. 2001;11(6 Suppl):S3-7.

25. Tsugane S, Sawada N. The JPHC study: design and some findings on the typical Japanese diet. Jpn J Clin Oncol. 2014;44(9):777-82.

26. van Donkelaar A, Martin RV, Brauer M, Hsu NC, Kahn RA, Levy RC, Lyapustin A, Sayer AM, Winker DM. Global Estimates of Fine Particulate Matter using a Combined Geophysical-Statistical Method with Information from Satellites, Models, and Monitors. Environ Sci Technol. 2016;50(7):3762-72.

27. Peters A. Air quality and cardiovascular health: smoke and pollution matter. Circulation. 2009;120(11):924-7.

28. Hanigan IC, Rolfe MI, Knibbs LD, Salimi F, Cowie CT, Heyworth J, Marks GB, Guo Y, Cope M, Bauman A, et al. All-cause mortality and long-term exposure to low level air pollution in the ' 45 and up study' cohort, Sydney, Australia, 2006-2015. Environ Int. 2019;126:762-70.

29. Ueshima H, Sekikawa A, Miura K, Turin TC, Takashima N, Kita Y, Watanabe M, Kadota A, Okuda N, Kadowaki T, et al. Cardiovascular disease and risk factors in Asia: a selected review. Circulation. 2008;118(25):2702-9.

30. Katanoda K, Sobue T, Satoh H, Tajima K, Suzuki T, Nakatsuka H, Takezaki T, Nakayama T, Nitta H, Tanabe K, et al. An association between long-term exposure to ambient air pollution and mortality from lung cancer and respiratory diseases in Japan. J Epidemiol. 2011;21 (2):132-43.

31. Raaschou-Nielsen O, Andersen ZJ, Beelen R, Samoli E, Stafoggia M, Weinmayr G, Hoffmann B, Fischer P, Nieuwenhuijsen MJ, Brunekreef B, et al. Air pollution and lung cancer incidence in 17 European cohorts: prospective analyses from the European Study of Cohorts for Air Pollution Effects (ESCAPE). Lancet Oncol. 2013;14(9):813-22.

\section{Publisher's Note}

Springer Nature remains neutral with regard to jurisdictional claims in published maps and institutional affiliations. 